\title{
Kontekstualisasi hukum murtad dalam perspektif sejarah sosial hadis
}

\author{
Ja'far Assagaf \\ Institut Agama Islam Negeri Surakarta \\ E-mail:dua_puteri76@yahoo.co.id
}

Apostasy is a conversion of the original Muslim, abandoning the faith and following other religion than Islam. In Islamic law, the perpetrator of apostasy will receive punishment of execution according to the jurists' consensus. The consensus is understood from some hadiths containing the command to execute the apostates and the fact of execution of apostates in the prophetic period of Muhammad saw. This article analyzes hadiths about the problematics of apostasy from the used terms, the background, and the contexts of the existance of command to execute apostates. The hadiths about apostasy were analyzed through socio-historical view of hadiths by the theory of compromise towards the seemingly contradictive hadiths. The result of analysis shows that the background of execution of apostates tended to the war situation in that period and the social crimes committed by the apostates, indicated by the existance of fact that the apostates committing religious crime, changing verses of al-Quran, received amnesty and were not executed. At present time, execution of apostates is a lively issue of debate. The result of analysis can provide other alternatives since apostate execution is not the only right way and it cannot be applied in any countries.

Murtad adalah perpindahan agama dari orang yang semula beragama Islam, keluar dan beragama lain selain Islam. Pelaku murtad dalam hukum Islam akan memperloleh hukuman berupa eksekusi mati menurut konsensus fuqaba. Konsensus tersebut dipahami dari beberapa hadis berisi perintah membunuh pelaku murtad dan fakta tentang eksekusi murtad di masa Nabi Muhammad saw. Tulisan ini menganalisa hadis-hadis terkait problematika murtad dimulai kosa kata, latar belakang, konteks adanya perintah eksekusi pelaku murtad. Hadis-hadis seputar murtad dianalisa melalui sejarah sosial hadis dengan teori kompromi terhadap hadis-hadis yang nampak kontradiktif. Hasil analisa menemukan bahwa eksekusi mati bagi pelaku murtad cenderung dilatar belakangi situasi perang saat itu dan tindak kejahatan sosial pelaku murtad, sebab terdapat pelaku murtad yang juga melakukan kejahatan religius; merubah ayat alQur'an ternyata memperoleh amnesti dan tidak dieksekusi mati. Masa kini eksekusi mati pelaku murtad ramai deperdebatkan. Hasil tulisan ini mungkin dapat membuka alternatif lain kalau eksekusi mati pelaku murtad bukan satu-satunya cara yang tepat dan tak dapat diterapkan di negara mana saja.

Keywords: Apostasy; Execution; Amnesty; History; Social context 
ljtihad, Jurnal Wacana Hukum Islam dan Kemanusiaan, Volume 14, No. 1, Juni 2014: 21-39

\section{Pendahuluan}

Memilih merupakan hak setiap orang, demikian ungkapan yang sering terdengar di tengahtengah masyarakat. Pilihan apapun yang telah diambil merupakan hasil dari pertimbangan rasa maupun rasio terhadap apa yang menjadi keputusan seseorang dalam memilih sesuatu, termasuk dalam memilih agama. Secara mendasar pilihan orang terhadap suatu agama merupakan hak individu bahkan merupakan bagian dari hak-hak Asasi manusia (HAM) yang memperoleh perlindungan melalui undang-undang.

Menjadi Muslim dan beragama Islam merupakan hak setiap orang tanpa ada paksaan (QS. al-Kāfirūn; 6; al-Gāshiah: 21-22) bahkan Islam tak melarang Muslim melakukan hubungan baik dengan non muslim yang tak memusuhi apalagi memerangi Muslim (QS. alMumtahạah: 8), sebab konsep universal Islam adalah memberi dan menebarkan kasih sayang di seluruh alam semesta (QS. al-Anbiyā': 107). Konsep Islam sebagai agama rahmat sering dipertanyakan pada era globalisasi. Pertanyaan sering kali muncul karena beberapa keputusan hukum (fikih) terkait dengan non Muslim, dinilai mediskreditkan bahkan terkesan menomor duakan komunitas non Muslim, baik dalam pembangunan rumah ibadah, keberagamaan, bahkan hak berpindah agama (baca; murtad).

Bila Islam sebagai agama rahmat telah memberikan hak setiap orang memilih agama, tentu hak yang sama harus diberi pada orang yang ingin mengganti keyakinannya sebagai muslim dengan agama selain Islam. Beberapa kalangan menilai praktek hukuman bagi pelaku murtad justeru menunjukkan Islam tidak sungguh-sungguh memberikan hak kebebasan memilih agama. Tulisan ini berusaha melacak akar permasalahan tersebut melalui konteks dan historis tentang hadis-hadis terkait dengan tindakan dan hukuman bagi pelaku murtad di masa Nabi saw.

\section{Definisi murtad (al-riddah)}

Murtad adalah kata yang sangat populer karena sanksi berat untuk mereka yang melakukan

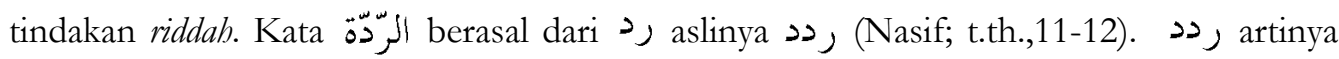
kembali dari sesuatu atau bekas (Faris; 1991, II, 386; al-Asfihaniy, t.th.,197; Jayb; 1998, 147). Orang yang kembali berarti menuju ke tempat semula yang masih ada bekasnya dahulu, atau meninggalkan bekas untuk mereka yang ditinggalkan. Orang yang meninggalkan Islam 
berarti kembali ke agamanya yang lalu, masih ada bekas saat ia masuk Islam atau meninggalkan kesan bagi orang lain saat ia masih Muslim.

Dalam al-Qur'an kata ر ג dengan berbagai derivasinya terulang 60 kali, 6 di antaranya dalam konteks riddah: QS. al-Baqarah:109 dan 217; Āli-'Imrān:100 dan 149; al-Mà'idah:54; Muḥammad:25 (Baqiy; 1994, 309-310). Ulama mendefinisikan riddah sebagai tindakan seseorang berpindah agama dari Islam menuju agamanya yang lama atau agama baru yang diyakini bahkan tidak beragama. Riddah dilakukan dengan keyakinan, kata-kata maupun perbuatan. Pelaku riddah disebut murtad karena ia kembali pada kekafiran yang pernah diyakini maupun menjadi kafir setelah menjadi Muslim. Dua kemurtadan ini disebut murtad al-millah atau murtad al-fitr. (Sanu: 2000, 219; Qal'ajiy dan Qanibiy, 1985: 221, 421; Jayb: 147; Ensiklopedi Hukum Islam: 1999/3: 304-305).

Hukuman mati bagi pelaku murtad cukup kontroversial karena bertentangan dengan Hak-Hak Asasi Manusia yang dicetuskan negara-negara Barat, terlebih secara mendasar Islam tidak memaksa orang untuk beragama (QS. al-Baqarah:256). Fuqahā' menilai murtad lebih identik dengan pelanggaran religius ketimbang publik (Sachedina, 2001: 98-99). Padahal di masa Nabi saw., terdapat indikator kuat kalau pelaku murtad dijatuhi hukuman mati bila ia melakukan kejahatan publik.

\section{Hadis-hadis tentang perintah membunuh pelaku murtad}

Konversi agama (baca; murtad) dinilai cukup kontroversial karena setiap individu berhak memilih agama yang ia yakini, sementara secara normatif terdapat perintah membunuh pelaku murtad (al-Bukhariy: 1994, II, 202, no. 3017; IV, 226, no. 6922):

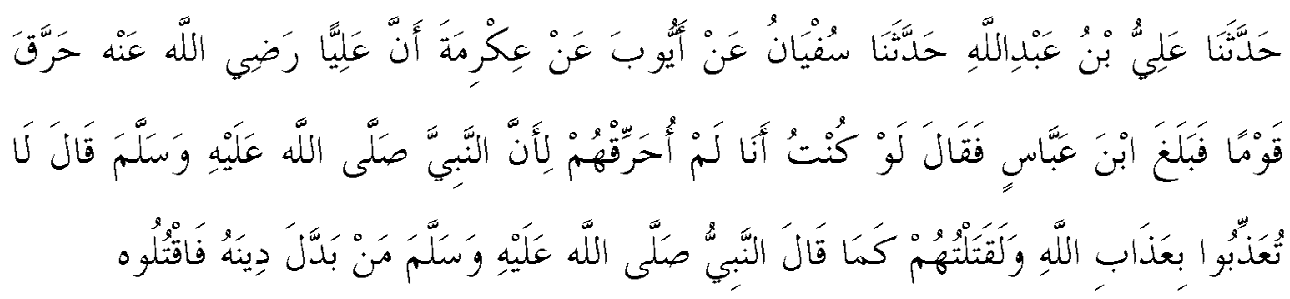

Terjemahnya:

"Sesungguhnya Ali telah membakar sekelompok orang, maka (ketika berita itu) sampai pada Ibn 'Abbas, ia berkata:'jika saya dalam posisi itu maka, tidak akan membakar mereka sebab Rasul saw. 
ljtihad, Jurnal Wacana Hukum Islam dan Kemanusiaan, Volume 14, No. 1, Juni 2014:21-39

bersabda:janganlah menyiksa orang seperti siksaan Allah swt'. Namun saya akan membunuh mereka karena Rasul juga bersabda:' barang siapa yang mengganti agamanya (murtad) maka bunublab orang tersebut".

Terdapat landasan normatif lain bagi fuqabä, melegalkan pembunuhan pelaku murtad (Muslim; 1993, II, 99-100, no. 1676):

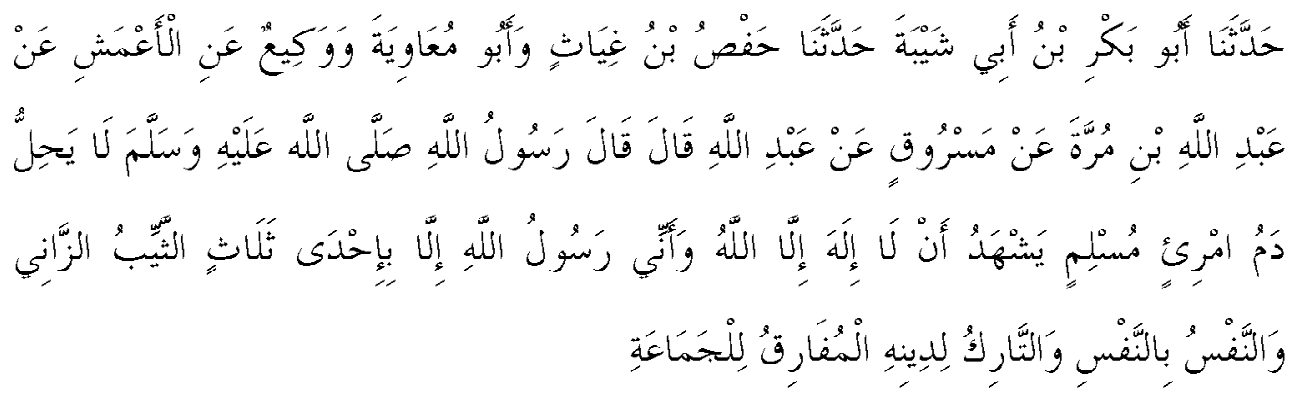

Terjemahnya:

"tidak halal darah seorang Muslim yang bersaksi tiada tuban selain Allab dan aku (Mub\}ammad) adalah utusan Allah, kecuali dengan salah satu dari tiga penyebab: 1) orang yang sudah kawin berzina; 2) jiwa (yang dibunuh diganti) dengan jiwwa dan ; 3) orang yang meninggalkan agamanya, yang berpisah dari jama 'ahnya (murtad)”.

\section{Analisa sanad dan matan hadis}

Riwayat al-Bukhari (194-256 H)

Hadis pertama riwayat al-Bukhari dari Ibn 'Abbas (w. $68 \mathrm{H}$ ), juga diriwayatkan oleh Abu Dawud (w. 275 H) (Dawud; 2003, IV, 112, no. 4351); al-Turmudhi (w. 279 H) (al-Turmudhi; 2003, III, 138, no. 1463); al-Nasa’i (w. 303 H) (al-Nasa’i; 1995, IV, vol VII, 109-111, no. 4065-4071); Ibn Majah (w. 273 H) (Majah; 2004, II, h. 50, no. 2535); Ibn Hanbal (w. 241 H) (Hanbal, t.th.,I, 217, 282-283, 322; V, 231). Sanad mereka bertemu dengan sanad alBukharipada Ayyub al-Shakhtianiy (w. $131 \mathrm{H}$ ) dari 'Tkrimah (w. $107 \mathrm{H}$ ) dari Ibn 'Abbas.

Pada redaksi matan terdapat beberapa jalur riwayat merinci peristiwa tersebut dengan perbedaan matan dengan al-Bukhariy, tapi tidak menyebabkan perbedaan substansi bahkan cenderung mirip antara redaksi satu dengan lainnya. Perbedaan dimaksud terletak pada kata بلد dalam al-Bukhari diganti dengan إرتد dalam riwayat 'Abd Razzaq (w. 211 H) dari 
'Aishah (w. 57 H) (1403 H, X, 114) dan al-Tabaraniy (w. 360 H) dari 'Asamah bin Malik alHadhmiy (al-Tabaraniy, 1983: XVII, 186). Riwayat lain mengganti kata بدل غيّر dengan

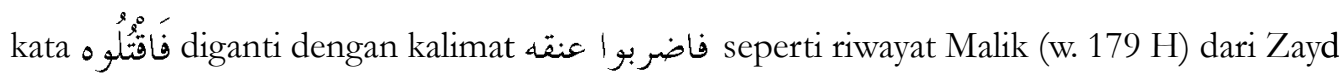
bin Aslam (w. 136 H) (Malik: 2005, 449, no. 1444). Sanad Malik bernilai mursal karena Zayd adalah tabi'in ('Imad,1998/I: 327), sementara riwayat al-Tabaraniy walau muttasil bernilai da îif karena ada al-Fadal bin Mukhtar (al-Haithamiy, 1988/IV: 261).

Semua perbedaan matan di atas tetap berisi instruksi membunuh pelaku murtad dan hadisnya bernilai sahịị. Ilustrasi agar pelaku murtad tetap dibunuh juga nampak ketika Ali kw (w. $40 \mathrm{H}$ ) membakar pelaku murtad dan Ibn 'Abbas tidak menyetujui tindakan itu, namun Ibn 'Abbas tidak menghalangi jika pelaku murtad dibunuh.

Riwayat Muslim (204-261 H)

Hadis kedua riwayat Muslim tentang halalnya darah mereka yang meninggalkan agama Islam juga diriwayatkan oleh Dawud (2003/IV: 112-113, no. 4352), al-Turmudhi (2003/ III: 101-102, no. 1407), al-Nasa'i (1995/IV: vol VII: 95, no. 4022; vol VIII: 13, no. 4730), Ibn Majah (2004/II: 49-50, no. 2534); Hanbal (t.th/I: 382, 428, 444, 465; VI, 181); alDarimiy (w. 255 H) (al-Darimy; 2005/II: 119, 152, no. 2295, 2445). Sanad mereka bertemu dengan sanad Muslim pada al-A'mash (w. 148 H) dari Abdullah bin Murrah (w. $100 \mathrm{H}$ ) dari Masruq (w. $63 \mathrm{H}$ ) dari Abdullah bin Mas'ud (w. $32 \mathrm{H}$ ).

Bila pelaku murtad harus dihukum maka bagaimana cara menghukuminya? Riwayat lain menjelaskan proses eksekusi terhadap pelaku murtad melalui 3 alternatif yaitu: dibunuh, disalib dan atau diasingkan, seperti penggalan hadis berikut (al-Nasa'i, 1995/IV, vol VII: 107, no. 4054):

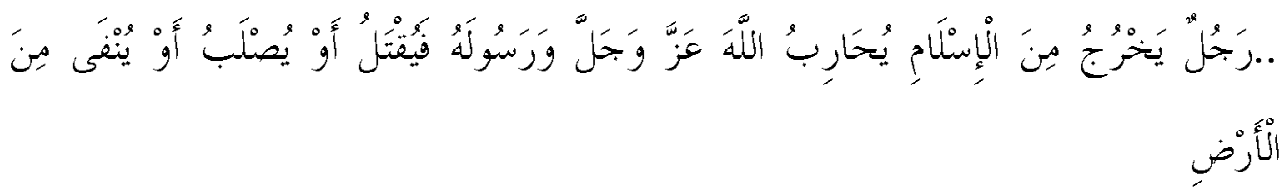

Dengan redaksi yang berdekatan, riwayat ini juga terdapat dalam Abu Dawud, (2003, IV, 113, 168, no. 4353, 4502), al-Turmudhi (2003/IV: 64, no. 2165), Majah (II: 49, no. 2533), al-Darimi (II: 119, no. 2294), Hanbal (t.th./I: 61,63, 65, 70; VI: 58, 205, 214). Hadis- 
ljtihad, Jurnal Wacana Hukum Islam dan Kemanusiaan, Volume 14, No. 1, Juni 2014:21-39

hadis mengenai halal darah orang yang murtad dari salah satu riwayat Abu Dawud dan dua riwayat Ibn Hanbal juga bersumber dari 'Aishah. Sanad Abu Dawud bertemu dengan sanad hadis riwayat al-Nasa'i pada Ibrahim bin Tahman (w. 168 H) dari 'Abd 'Aziz bin Rufai' (w. 130 H) dari 'Ubaid bin 'Umair (w. $68 \mathrm{H}$ ) dari 'Aishah. Dua sanad Ibn Hanbal bertemu dengan sanad hadis riwayat al-Nasa'i pada 'Aishah melalui 'Amar bin Galib (w. $\pm 110 \mathrm{H}$ ), sementara sanad alTurmudhi, al-Darimi dan Ibn Majah bermuara pada 'Uthman bin 'Affan (w. 35 H).

Kata 2 حرب riwayat al-Nasa’i tersebut berarti merampas (al-Athir, t.th/ I: 358) lalu diartikan dengan memerangi dan melanggar (Anis, t.th./I: 163). Dalam konteks ini, kata tersebut berarti memerangi sebab tindakan murtad sudah pasti melanggar hak Allah Swt. Penyebutan kata يُنَى sebagai tindakan memerangi agama. Adapun kata dari penggalan hadis di atas lebih tepat berarti pelaku murtad diasingkan dari negerinya. Bila

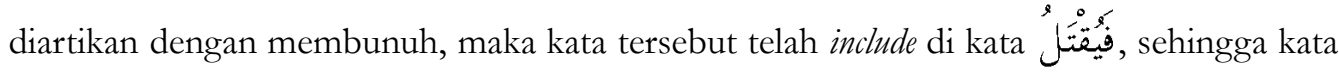
نفى diartikan menjauhkan atau mengasingkan (Manzur, t.th/ XV: 336-337) sebagaimana QS. al-Måridah:33.

Hadis riwayat Muslim dan hadis pertama dari al-Bukhariberisi legalisasi hukuman mati bagi pelaku murtad. Melalui pengertian kosa kata di atas, menjelaskan pelaku murtad akan dieksekusi bila dibarengi dengan memusuhi Allah dan Rasulullah saw. Pemaknaan ini membutuhkan penjelasan lanjut, sebab hadis sebelumnya riwayat al-Bukhari secara teks berisi perintah membunuh siapa saja yang murtad.

Dalam hadis lain disebutkan, pelaku murtad ada yang dieksekusi karena melakukan pelanggaran religius semata dan ada yang melakukan kejahatan publik, namun ada pula pelaku murtad yang diamnesti dan ia tidak melakukan kejahatan publik. Agar dapat dipahami lebih detail dan komprehensif, perlu dipaparkan hadis-hadis terkait praktek eksekusi mati terhadap pelaku murtad.

\section{Praktek eksekusi pelaku murtad di masa nabi Muhammad Saw.}

Kisah suku Ukl dan Uraynah

Suku 'Ukl dari bani Taîm al-Ribab turunan `Adnân. Suku 'Uraynah dari turunan Qahtan. Suku 'Uraynah disini dari bani Bajilah, karena dalam suku 'Uraynah ada bani Bajilah dan 
Qudāa'ah (Hajar, 2000/I: 449). Peristiwa kedatangan dan murtadnya suku 'Ukl dan 'Uraynah diriwayatkan sahabat Anas (al-Bukhari, 1994/III: 46-47, no. 4192):

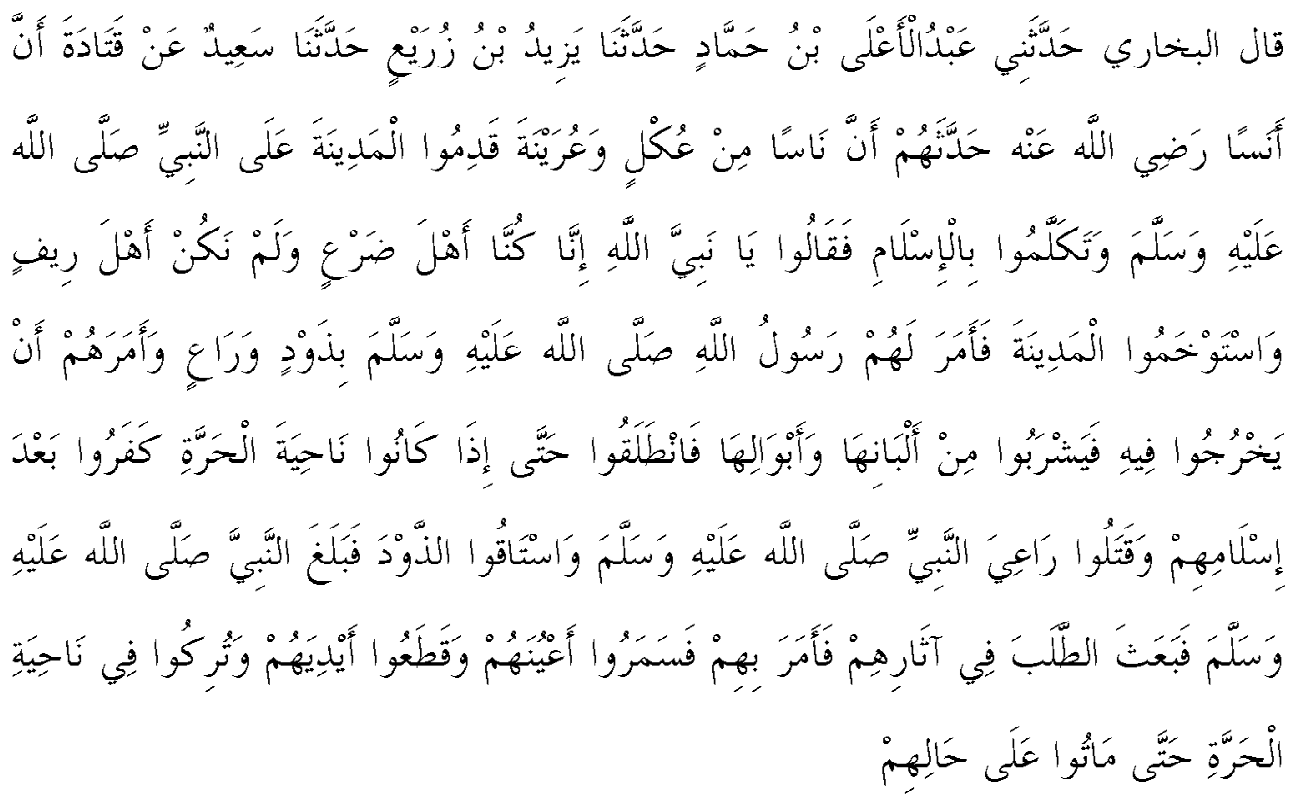

Terjemahnya:

"Sekelompok orang dari suku Ukl dan Uraynah datang ke Madinah menemui Nabi saw. dan membicarakan tentang Islam (masuk Islam dalam riwayat lain). Mereka berkata:' ya Nabi Allah, sesungguhnya kami ini berasal dari tempatyang gersang dan tidak subur. Mereka memandang Madinah tidak cocok (karena penyakit yang mereka alami), maka Rasul Saw. memerintabkan mereka (memberikan) unta (antara 3-10 ekor) dan pengembala serta memerintabkan agar keluar (memanfaatkan unta). Kemudian mereka meminum susu dan kencing unta tersebut. (setelah selesai) mereka lalu pergi sehingga tiba di daerah pasir dan bebatuan. Pada saat itu mereka murtad dan membunuh pengembala Nabi Saw. tersebut, unta-unta itu kemudian mereka giring (curi). Info tersebut sampai pada Nabi Saw., lalu ia mengutus beberapa sahabat mencari jejak mereka dan memerintabkan (untuk bertindak). Akhirnya sahabat mencongkel mata dan memotong tangan pelaku murtad tersebut, dan membiarkan mereka di tempat itu sampai menemui ajalnya".

Riwayat ini memuat secara lengkap suku 'Ukl dan 'Uraynah menemui Rasul saw. Kedatangan kedua suku tersebut diperkirakan terjadi pada $\pm 6 \mathrm{H}$ setelah Hudaybiyyah walau sejahrawan belum sepakat di bulan apa (Sa'ad, t.th./II: 93; Hajar, 2000/I: 449). Riwayat Muslim dan Ibn Hanbal memuat kedatangan suku 'Ukl berjumlah 8 orang tanpa menyebutkan 
ljtihad, Jurnal Wacana Hukum Islam dan Kemanusiaan, Volume 14, No. 1, Juni 2014: 21-39

jumlah personil suku 'Uraynah (Muslim, 1993/II: 96, no. 1671; Hanbal, t.th./III:186, juga 163,170,177,205, 233, 287, 290). Riwayat al-Bukhari sendiri tidak mengungkap secara jelas apakah mereka masuk Islam atau tidak, tapi keislaman mereka nampak dalam riwayat alNasa’i (IV, vol. VII: 101, no. 4035; 99-103, no. 4031-4040) dan lainnya tentang kemurtadan suku 'Uraynah yang datang ke Madinah tanpa menyebut suku 'Ukl (Dawud/IV: 117-119, no. 4364-4367, 4369; al-Turmudhi/I: 132-133, no. 72; IV: 6, no. 2049; Majah/II: 63, no. 2578-2579).

Kehadiran kedua suku tersebut di Madinah tidak berlangsung lama. Mereka tidak cocok dengan udara atau mengalami gangguan pencernaan akibat cuaca. Kondisi ini dipahami dari kata استو خخو dalam riwayat al-Bukhary, berarti memberatkan seseorang karena ia tidak cocok untuk tinggal. Arti ini mirip dengan kata l اجتو و pada riwayat al-Nasa'i yang disinyalir, yaitu cuaca yang tidak mendukung kesehatan yang dapat menyebabkan sakit pada bagian pencernaan (Hajar, 2000/I: 449-450; Anis, t.th./II: 1019). Dua kata tersebut menunjukkan sesuatu yang memberatkan mereka karena penyakit di lambung yang disebabkan makanan. Kondisi ini menjadi penyebab Rasul saw. menyuruh agar mereka

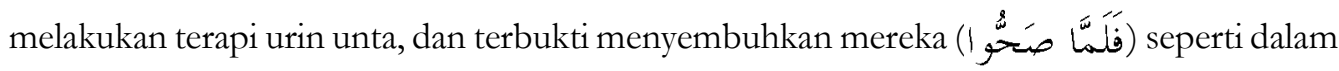
riwayat al-Nasa'i (1995/IV: 101, no. 4035). Setelah sembuh, suku 'Ukl dan 'Uraynah malah membunuh gembala utusan Nabi Muhammad Saw. bernama Yasar al-Nawby, akhirnya mereka juga dibunuh setelah \pm 20 pemuda Ansar, dipimpin oleh Sa'id (Sa'ad) bin Zayd alAshhaliy berhasil menyusul dan membalas perbuatan mereka (Hajar, 2000/XI: 452; alBukhari, 1994/III: 46).

Kata سم dalam riwayat al-Bukhari, awalnya berarti warna di antara hitam dan putih atau diartikan dengan gelap. Orang yang dibutakan berarti tidak bisa melihat, gelap pandangannya. Karena itu, kata tersebut juga berarti membutakan (Manzur, t.th./IV: 376-378). Dalam riwayat al-Nasa’i tersebut, kata سمر diganti dengan kata berarti mencongkel mata dengan besi yang panas atau dengan sesuatu yang tajam. Makna yang disebut terakhir memiliki kesamaan arti dengan kata samara (Hajar, 2000/XI: 453) Tindakan itu sebagai balasan atas perbuatan suku 'Ukl dan 'Uraynah (Muslim, 1993/II: 97, no. 1671). Pemaparan ini juga menandaskan kedua suku itu dihukum karena mereka melakukan kejahatan publik. 
Kontekstualisasi hukum murtad dalam perspektif sejarah sosial hadis (Ja'far Assagaf)

Kisah Yahudi di Yaman

Kisah Yahudi Yaman yang murtad lalu dieksekusi akan kontradiktif dengan murtadnya suku 'Ukl dan 'Uraynah dilihat dari aspek pelanggaran publik. Kedua suku tersebut melakukan kejahatan publik, sementara Yahudi itu tidak melakukannya seperti riwayat dari sahabat Abu Musa al-Ash'ari (w.50 H) (Hanbal; t.th./IV: 409):

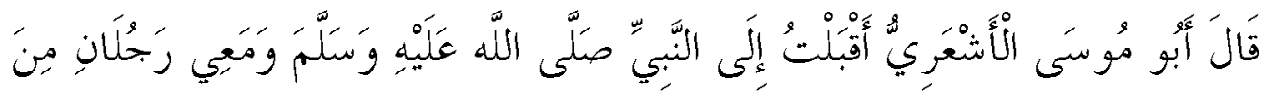

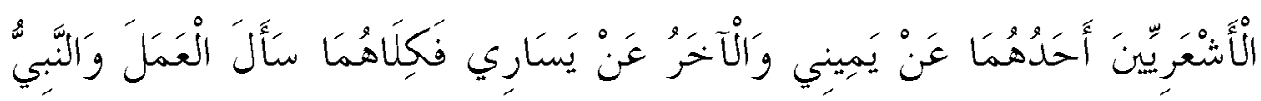

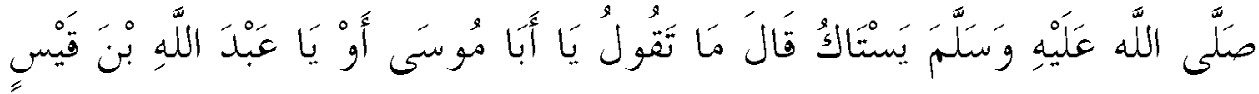

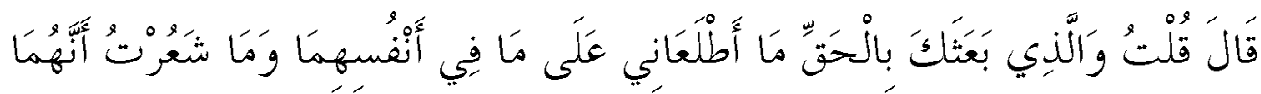

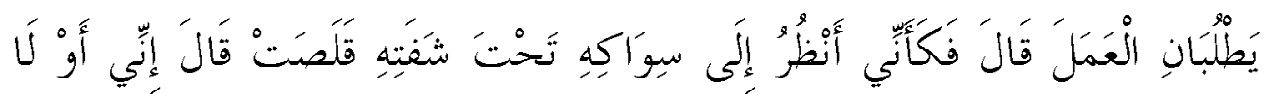

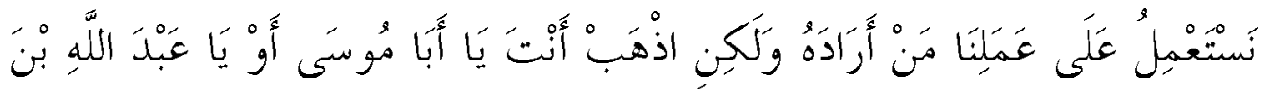

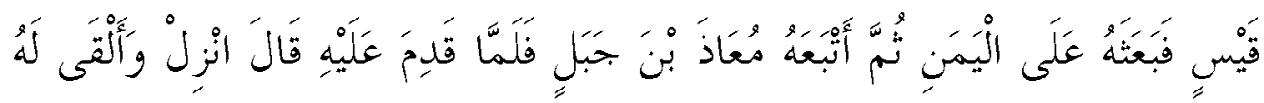

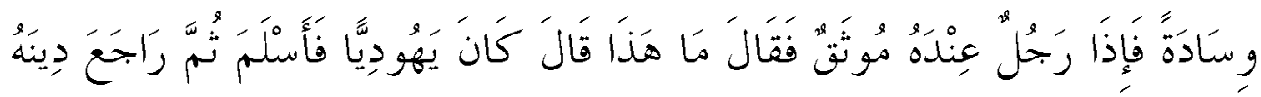

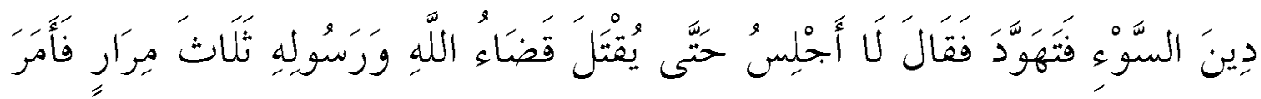

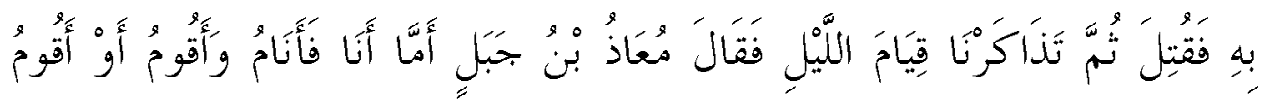

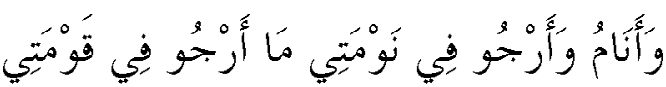

Terjemahnya:

"Saya (Abu Musa al-Ash'ari) datang pada Rasulullah saw bersama dua orang dari suku Ash"ary. Salah satu di antara mereka berada di sebelah kanan dan lainnya di sebelah kiri. Keduanya meminta pekerjaan (jabatan di Yaman), yang pada saat itu Nabi saw (diam) sedang bersiwak'. Rasul saw bersabda: 'apa yang engkau (ingin) katakan hai Abu Musa atau 'Abdullab bin Qays berkata perawi (ragu mana yang disebut). Saya (Abu Musa) menjawab:'demi yang mengutusmu dengan kebenaran, mereka berdua tidak membukakan (membicarakan) padaku apa yang mereka inginkan (dari 
ljtihad, Jurnal Wacana Hukum Islam dan Kemanusiaan, Volume 14, No. 1, Juni 2014: 21-39

kedatangan mereka), dan saya tidak merasa mereka akan meminta pekerjaan (berbuat seperti ini dengan meminta jabatan)'. Saya (sempat) melihat siwaknya Rasul saw di bawab bibirnya bergeser, lalu beliau bersabda:' sesunggubnya saya atau kami tidak akan memberikan pekerjaan (jabatan) bagi mereka yang memintanya. Tetapi engkau hai Abu Musa atau 'Abdullah bin Qays pergilah, maka Nabi saw mengutusnya ke Yaman. Kemudian Mu'adh bin Jabal menyusul dan tatkala sampai, berkata Abu Musa:'turunlah (dari kendaraanmu)' dan ia meletakean bantal (sebagai penghormatan) pada Mu'adh. (sedangkan) Di samping Abu Musa ada seseorang yang terikat, Mu'adh berkata: apa ini, Abu Musa menjawab:dia Yahudi yang masuk Islam tetapi kembali menjadi Yahudi lagi (murtad). Mu'adh menimpali: Saya tidak akan duduk sehingga ia dibunuh, inilah ketentuan Allah dan RasulNya, tiga kali ia berkata demikian. Kemudian Yahudi tersebut dibunuh. (Setelah selesai), kami berbincang-bincang mengenai shalat malam, Mua'dz berkata:'saya bangun dan (kemudian) tidur atau sebaliknya, dan saya mengharapkan melalui) tidurku ini bisa dapat beribadah dengan baik saat bangun nanti”.

Dengan matan yang mirip dan ringkas, hadis ini juga diriwayatkan al-Bukhari(1994/IV: 226, no. 6923) dan terulang sekitar 11 kali dalam Șhahịh al-Bukhäri; Muslim (1995/II: 186, no. 1824); Dawud (2003/IV: 113-114, no. 4354); al-Nasa'i (1995/I: 27, no. 4). Sanad mereka bertemu dengan sanad Ibn Hanbal pada Yahya bin Sa'id al-Qattan (w. 198 H) dari Qurrah bin Khalid (w. 154 H) dari Humayd bin Hilal dari Abu Burdah (w. 104 H) dari Abu Musa (w. $\pm 50 \mathrm{H}$ ).

Dalam riwayat Ibn Hanbal di atas, dilustrasikan Yahudi tersebut sedang terikat (diborgol/ (مُثَتَ Musa ke Yaman. Keheranan Mu'adh hilang setelah Abu Musa berkata: , salah satu versi al-Bukhari menyebut secara ringkas tapi padat ( ثُّمّ ارتدَّ (al-Bukhari/III:71, no. 4344/45).

Dari tinjauan matan, tidak terdapat hadis yang kontradiktif sekalipun dalam mengisahkan jalannya peristiwa itu terdapat versi berlainan. Riwayat Ibn Hanbal di atas dan versi alBukhary, keduanya saling mendukung tetang pengutusan dua sahabat tersebut ke Yaman dan eksekusi Yahudi dimaksud, yang terjadi sebelum atau setelah perang Tabuk di tahun 9 H, karena Mu'adh dan Abu Musa mengikuti perang tersebut (Sa'ad, t.th./III: 590; Ibn Hajar, 2000/VIII: 387, 449), hanya al-Bukharimenginformasikan pengutusan kedua sahabat tersebut sebelum perang Tabuk. 
Eksekusi Yahudi Yaman tidak hanya kontra dengan eksekusi suku 'Ukl dan 'Uraynah, tapi juga dengan amnesti Nabi saw. terhadap Ibn Abi Sarh yang juga murtad.

Amnesti terhadap 'Abdullah bin Abi al-Sarb (w. 57/59 H)

Saat Fath Makkah (8 H), beberapa tokoh kuffar masuk dalam daftar hitam yang harus dibunuh disebabkan perbuatan dan propaganda mereka atas Islam, termasuk Ibn Abi Sarh (Dawud, 2003/II: 410, no. 2683-2684):

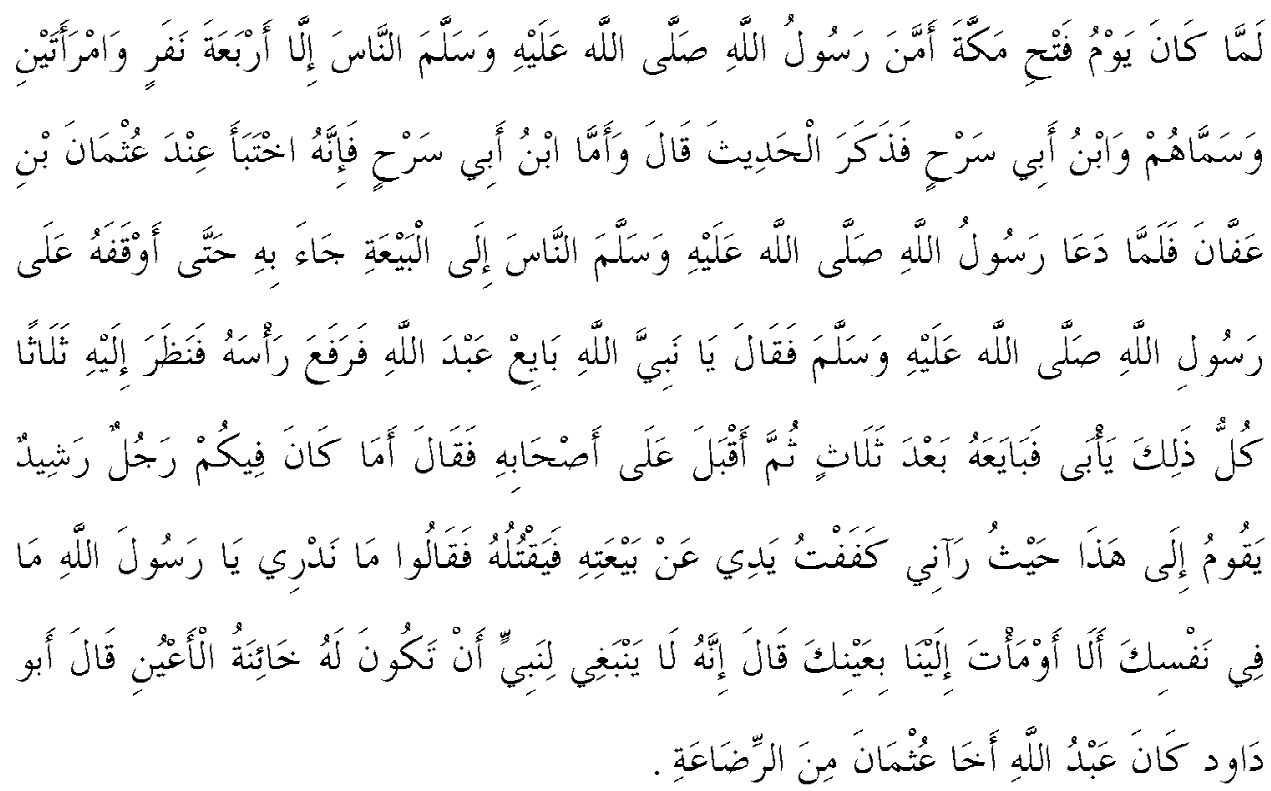

Terjemahnya:

"Ketika Fath al-Makkeah, Rasul saw memberikan jaminan keamanan pada semua orang kecuali 4 lelaki dan 2 wanita. Lalu Sa'ad menyebutkan orang-orang tersebut, Ibn Abi Sarh termasuk di dalamnya. Sa'ad menyebutkan hadis tersebut, dia berkata: 'adapun Ibn Abi Sarb berlindung pada 'Uthman bin 'Affan. Tatkala Rasulullah saw memanggil orang-orang untuk berbaiat. 'Uthman datang dengan Ibn Abi Sarh hingga dia memberhentikan (Ibn Abi Sarh) tepat berada pada Rasulullah saw. 'Uthman berkata:' ya Nabi Allah (terimalah) bai at Abdullah. Nabi saw mengangkat kepalanya dan melihat Abdullah 3 kali. Semuanya mengindikasikan Nabi enggan menerimanya. Setelab lebih 3 kali, Nabi membaiat Abdullah. Kemudian (setelah itu) Nabi saw menghadap para sahabatnya dan bersabda:'apakah ada di antara kalian orang yang dapat mengambil petunjuk (pandai) dalam peristiwa ini saat melihat saya tidak membaiat Abdullah, maka bunulah dia'. Sahabat menjawab:'kami 
ljtihad, Jurnal Wacana Hukum Islam dan Kemanusiaan, Volume 14, No. 1, Juni 2014: 21-39

tidak tahu apa yang kamu inginkan ya Rasulullah saw, tidakkah (saat itu) engkau memberi isyarat pada kami dengan matamu? Nabi Saw. bersabda: sesunggubnya tidak pantas bagi seorang Nabi khianat mata (berlaku curang)"'. Abu Daud berkata:' 'Abdullah adalah saudara sesusuan 'Uthman'.

Terkait amnesti untuk Ibn Abi Sarh tersebut, al-Nasa'i memuat lebih rinci peristiwa itu berisi instruksi Nabi Saw., untuk membunuh personil tertentu melalui penggalan hadis Ungkapan tersebut berisi kesungguhan menghukumi mereka yang jelas berbuat kejam pada Islam, termasuk pelaku murtad. Riwayat tersebut juga menyebutkan eksekusi mati Ibn Khatal dan Miqyas bin Subabah karena murtad (al-Nasa'i, 1995/IV, vol. VII: 111-112, no. 4073), namun Abdullah bin Sa'ad bin Abi Sarh yang pernah menjadi penulis wahyu, selamat melalui jaminan 'Uthman ra (w. $35 \mathrm{H}$ ) sebagaimana terlihat dalam riwayat Abu Daud di atas.

Sanad al-Nasa'i dengan sanad Abu Daud bertemu pada Ahmad bin Mufaddal (w. 215 H) dari Asbat (w. \pm 198 H) dari al-Suddiy (w. 127 H) dari Mus'ab bin Sa'ad (w. 103 H) dari Sa'ad bin Abi Waqqas (55/56/57 H). Peristiwa murtadnya Ibn Abi Sarh dan mendapat amnesti Nabi saw atas jaminan Utsman adalah berita masyhur yang tak mungkin ditutupi sebab terdapat juga di beberapa kitab hadis seperti al-Mustadrak (al-Hakim, 1990/III: 47); Sunan al-Kubra (al-Bayhaqiy, 1994/VII: 40; VIII: 205) dan kitab sejarah seperti al-Sïrah alNabawiyyah (Hisyam, 2004/II: 316); al-Kamil fí al-Tarikh (al-Athir, 1979/II: 249).

Menilik peristiwa amnesti atas Ibn Abi Sarh dapat menimbulkan pertanyaan kenapa Ibn Abi Sarh memperoleh amnesti sedangkan Miqyas dan lainnya dibunuh? Sebelum melihat latar belakangnya, perlu dipahami lebih awal kata اخختبأ dalam riwayat Abu Dawud, berarti bersembunyi atau berlindung (al-Sindi dalam al-Nasa’i/ IV, vol. VII: 111; Anis, t.th./I: 213). Abdullah saat itu berlindung pada 'Uthman melalui dua pendekatan: (1) 'Uthman sesusuan dengan Ibn Abi Sarh; (2) 'Uthman dekat dengan Nabi saw. Menurut al-Sindi al-Hanafi

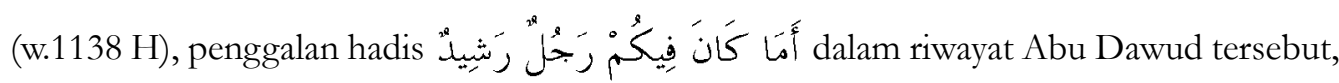
berarti orang cerdik untuk mengambil suatu keputusan yang tepat (al-Sindi dalam al-Nasa'i) IV, vol. VII: 111). Saat itu Nabi saw. membutuhkan orang yang mengerti dengan diamnya beliau, agar membunuh Ibn Abi Sarh. 
Semua jalur sanad hadis tentang amnesti atas Ibn Abi Sarh bernilai $\frac{1}{\mathcal{C}} /$ sălih (Hajar, 1964/III: 130) menyisakan pertanyaan, benarkah pelaku murtad yang tidak melakukan kejahatan publik juga harus dibunuh?. Fakta Rasulullah Saw. ingin mengeksekusi Ibn Abi Sarh seperti dipahami dari berbagai penggalan kalimat di atas. Bila begitu, apakah hanya karena jaminan 'Uthman yang dekat dengan Nabi Saw., sehingga eksekusi terhadap Ibn Abi Sarh menjadi batal?.

Pertanyaan di atas memunculkan pemahaman lebih substansi, bila pelaku murtad harus dihukum mati maka siapapun dia tentu harus pula dieksekusi. Kasus Ibn Abi Sarh, mengindikasikan terdapat kemungkinan pelaku murtad diamnesti, jika mereka tidak melakukan kejahatan publik.

\section{Pemahaman kontekstual hadis tentang murtad dan hak memilih agama}

Meninjau kembali beberapa hadis terkait dengan konversi agama (baca; murtad) dan praktek eksekusi mati di masa Nabi Muhammad Saw., memunculkan kontradiktif, sebab terdapat amnesti Rasulullah Saw. terhadap pelaku murtad bernama Abdullah bin Abi Sarh. Di sisi lain, nampak kontras karena suku 'Ukl dan 'Uraynah yang murtad dibunuh atas perintah Nabi Muhammad Saw.

Berdasarkan riwayat, suku 'Ukl dan 'Uraynah dihukum mati karena dua alasan: (1) mereka telah membunuh dan (2) murtad. Kondisi ini akan sedikit kontradiktif dengan kisah eksekusi Yahudi di Yaman akibat murtad atas perintah Mu'adh ra pada Abu Musa di zaman Nabi saw, karena Yahudi dimaksud tidak melakukan pembunuhan yang mungkin masih bisa diampuni bila dianalogikan pada kasus Abdullah bin Abi Sarh.

Diakui memang pelik bahkan mungkin lebih rumit bila kasus murtad diperhadapkan dengan landasan Islam tentang tidak ada paksaan memilih agama (QS. al-Baqarah: 256), karena itu beberapa kasus di atas harus dilihat lebih spesifik terkait hadis-hadis yang berisi perintah membunuh pelaku murtad. Terungkap pernah ada eksekusi terhadap suku 'Ukl, 'Uraynah dan Yahudi Yaman karena murtad, namun sebagaimana terbaca kalau kedua suku tersebut dihukum lantaran mengacaukan tatanan sosial masyarakat. Landasan ini jika dipakai maka Yahudi Yaman tidak boleh dibunuh oleh Mu'adh dan Abu Musa, sebab Yahudi tersebut tidak melakukan kejahatan publik sebagaimana kasus kedua suku di atas, dan atau 
ljtihad, Jurnal Wacana Hukum Islam dan Kemanusiaan, Volume 14, No. 1, Juni 2014: 21-39

Yahudi itu bukan orang sepenting Abdullah bin Abi Sarh.

Kasus Ibn Abi Sarh lebih berat ketimbang murtadnya Yahudi Yaman, sebab Ibn Abi Sarh sebelum murtad termasuk penulis wahyu, bahkan ia pernah berusaha melakukan distorsi beberapa kata al-Qur'an (al-Tabari, 1407/II: 218; al-Athir, 1979/II: 249). Adapun Yahudi Yaman sebagaimana data yang ada, tidak ditemukan indikator kalau dia tokoh masyarakat atau orang penting di komunitasnya. Yahudi itu dapat dianggap rakyat biasa, yang secara politik maupun sosial tidak memiliki pengaruh apa-apa terhadap kelangsungan penyebaran risalab Islam.

Dalam dua kasus murtad di atas, penulis melihat tiga hal yang menyebabkan muncul kebijakan yang berbeda: (1) hukuman yang harus ditimpakan pada Abdullah adalah dibunuh, namun karena ada jaminan maka Abdullah diampuni; (2) Harus dilihat kalau kasus Abdullah bin Sa'ad bin Abi Sarh langsung ditangani oleh Rasul saw., sedangkan kasus Yahudi Yaman dihadapi oleh sahabat. Nabi saw. mengetahui kasus Yahudi melalui informasi dari kedua sahabat tersebut. Mu'adh maupun Abu Musa berada di tempat tugas mereka yaitu Yaman sampai Nabi saw. wafat $11 \mathrm{H}$. Mu'adh sendiri menurut riwayat yang mashhur, kembali ke Madinah di masa awal khalifah Abu Bakar ra, akhir $11 \mathrm{H}$. Penulis tidak memperoleh data kapan Abu Musa kembali ke Madinah. Selain fakta tersebut, juga terdapat surat Rasul saw. kepada para sahabat di Yaman. Saat itu, Mu'adh sebagai motifator dari sekian sahabat Nabi Saw. di Yaman untuk memendam gerakan al-Aswad al-'Unsiy sebagai nabi palsu. Al-Aswad terbunuh di Yaman di saat-saat terakhir kehidupan Rasul saw. di Madinah. Karena itu, surat yang $\mathrm{Mu}$ 'adh kirim berisi kematian al-'Unsiy mendapat balasan surat dari Abu Bakar ra sebagai khalifah baru (Sa'ad, t.th./III: 585; VII: 388; al-Athir, 1979/II: 336-341, 383; Hajar, VI: 137).

Dengan fakta ini, penulis cenderung bila Nabi saw. yang menghadapi langsung kasus Yahudi Yaman, maka ada kemungkinan diamnesti karena Yahudi tersebut walaupun telah melakukan pelanggaran religius, namun ia tidak melakukan kejahatan publik. Dia masih mungkin memperoleh amnesti melalui alasan ke (3) bukan hanya Abdullah bin Abi Sarh yang harus dibunuh, tetapi terdapat juga Abdullah bin Khatal dan Miqyas bin Subabah. Kedua orang ini juga dibunuh bukan karena murtad saja, tapi mereka juga membunuh orang Muslim. Abdullah bin Khatal ketika murtad, membunuh pembantunya yang Muslim, 
ia juga termasuk propagandis yang melecehkan Islam dan Rasul saw. melalui dua anak buahnya. Sementara Miqyas bin Subabah selain murtad, ia juga membunuh seorang Ansar (Hisyam, 2004/IV: 316-317; al-Tabari, 1407/II: 110,160; al-Athir, 1979/II: 249-250).

Seperti telah disinyalir ada konsensus fuqah $\vec{a}$ tentang eksekusi mati pelaku murtad (alMaqdisi, 198/IX:16; al-Nawawi, 2000/VI, vol. XII: 164) secara umum mereka beralasan bahwa tindakan murtad dapat membahayakan agama itu sendiri maupun tatanan masyarakat Islam (Shuhbah, 1974: 325) bahkan dapat melahirkan bahaya yang lebih jauh terhadap Negara (Baidhawy, 2006: 119). Kedua alasan ini menjadi tepat bila dilihat pada konteks historis di masa Nabi Saw., masa itu hubungan antara Muslim dengan non Muslim khususnya musyrik dalam situasi perang. Kasus murtad dapat dinilai sama dengan pembelotan militer di masa kini.

Berpijak dari fakta di atas, eksekusi mati bagi pelaku murtad lebih tepat dilihat sebagai pelanggaran sipil atau kejahatan publik dan bukan pelanggaran religius. Menurut Sachedina, para fuqah $\vec{a}$ belum melakukan telaah lebih mendalam tentang perintah legal tertentu dalam al-Qur'an, termasuk masalah konversi agama yang juga dianut oleh agama misi lain seperti Kristen dalam surah Ulangan 17: 1-7 menyatakan pelaku murtad harus dikeluarkan dari gerbang kota lalu dirajam dengan batu sampai mati. Menurutnya, perbedaan antara aspek religius dan sipil dalam Islam bukan merupakan perbedaan de jure, namun perbedaan itu layak disebut sebagai de facto. Tapi ia mengakui bahwa untuk membedakan kedua hal tersebut tidaklah mudah. Sebab itu, sekalipun Sachedina setuju bahwa pelaku murtad hanya bisa dihukum oleh Allah, karena melanggar ḥuqūq Allāh. namun ia juga tidak menyalahkan pelakunya dieksekusi mati, bila kemurtadan tersebut membahayakan publik masyarakat (Sachedina, 2001: 98-101; Little, 1997: 110-112)

Sachedina seperti penulis lain (Sachedina, 2001:100; Little, 1997: 113-118; Khadduri, 2006: 77) sering mengemukakan contoh tindakan riddah dari beberapa suku Arab setelah Rasul saw. wafat adalah kurang tepat. Sebab fakta-fakta di atas membuktikan bahwa tindakan riddah yang dilakukan secara personil akan dijatuhi hukuman, bila tindakan tersebut membahayakan publik masyarakat. Memang kalau Sachedina memandang pelanggaran hak tuhan dan hak manusia melalui tindakan riddah, menandaskan bahwa aspek religius dan aspek sipil ada saling ketergantungan dalam hukum untuk menata komunitas Muslim 
ljtihad, Jurnal Wacana Hukum Islam dan Kemanusiaan, Volume 14, No. 1, Juni 2014: 21-39

(Sachedina, 2001: 99), maka hal itu juga mesti berlaku pada tindakan kejahatan publik yang dilakukan walaupun hanya seorang seperti tindakan Miqyas, mengingat ada unsur mengacaukan tatanan komunitas Muslim.

Dalam konteks kekinian muncul pemikiran untuk meniadakan eksekusi mati terhadap pelaku konversi agama, termasuk di negara yang berlandaskan syari'at Islam. Dengan alasan bahwa di era globalisasi ini, belahan dunia manapun telah menjadi persinggungan agamaagama besar maupun kecil. Dalam sebuah negara Islampun terdapat beragam etnis, suku, budaya termasuk agama. Karena alasan ini dan penegakkan hak-hak asasi manusia (HAM), pendapat ini menganggap eksekusi mati akibat dari konversi agama tidak relevan lagi, dan patut ditiadakan (Baidhawy, 2006:126-127).

Perlu diberi catatan dari pendapat di atas sebagai berikut; 1) Islam sekalipun sebagai agama universal untuk umat manusia, namun memberikan hak pilih pada setiap individu untuk memilih agama yang ia yakini. Islam tidak memaksa kepada individu manapun untuk menjadi seorang Muslim, namun di saat yang sama bila orang tersebut telah memilih menjadi Muslim, secara otomatis ia mesti terikat dengan peraturan Islam. Konsekuensi ini sangat rasional, kalau tidak demikian maka setiap orang dapat berganti agama sesuka hati dengan menjadikan agama sebagai mainan. Selain itu, murtad akan berubah sebagai produk yang membentuk ambivalen dalam jiwa pelakunya. Berkepribadian ganda kapanpun sangat tercela terutama bagi sebuah negara yang membutuhkan kesetiaan setiap warganya. Analogi ini cukup sederhana karena fenomena yang ada menerangkan tidak sedikit orang dieksekusi mati, hanya karena ia berkhianat pada negara, organisasi (Shuhbah, 1974: 324-325) bahkan melakukan transaksi narkoba yang menyebabkan rusaknya tatanan sosial, atau dengan membocorkan rahasia negara. Bukankah tindakan konversi agama juga merupakan sebuah bentuk penghianatan dan bila dibiarkan begitu saja dapat menyebabkan setiap orang mempermainkan agama?; 2) dengan hak asasi manusia, seyogyanya setiap negara diberi kebebasan mengatur rumah tangganya. Permasalahan konversi agama layak dikembalikan kepada setiap negara yang menganut hukuman tersebut tanpa ada campur tangan pihakpihak tertentu. Dengan begitu, HAM bisa dirasakan negara manapun tanpa ada diskriminasi. Dewasa ini, Arab Saudi, Pakistan, Sudan dan Malaysia memberlakukan hukum mati bagi pelaku konversi agama (Baidhawy, 2006: 124-126; Kasimin, 1990: 66-71); 3) Hukum mati 
terhadap pelaku konversi agama (murtad) dapat dibatalkan dengan melihat konteks tertentu dan tidak mesti hukuman mati adalah satu-satunya cara menghukumi mereka yang murtad sebagaimana kasus Abdullah bin Abi Sarh, atau bahkan dapat diganti dengan hukum lain yang memiliki kesan jera.

Beragam analisa di atas, menjelaskan murtad secara mendasar tetap dihukum dengan kualifikasi bila tindakan itu membawa dampak sosial, dan tidak mungkin diterapkan di negara yang tidak berlandaskan syari'at Islam seperti Indonesia.

\section{Daftar pustaka}

Anis, Ibrahim dkk. Mu'jam al-Wasit. Juz I-II. Cairo: tp, t.th.

Al-Asbahi, Malik bin Anas. Muwatta’' Mālik bi Riwāyah al-Laythiy. Beirut: Dār al-Fikr, 2005.

Al-Asfihani, Raghib. Mujjam Mufradât al-Fåal-Qur'an. Ditahqiq oleh Nadim Mar'ashliy. Beirut: Dār al-Fikr, t. th.

Al-Asqalani, Ibn Hajar Ahmad bin Ali. Fatḥ al-Bäriy bi Sharḥ Shaḥị̣ al-Bukbäriy. Juz I, VIII, XI, XIV. Beirut: Dār al-Fikr, 2000.

Al-Asqalani, Ibn Hajar Ahmad bin Ali. al-I sāabah fì Tamyìz al-Ṣahāabah. Juz IV, VI. Diedit oleh 'Ali Muh \}ammad al-Bujāwiy. Beirut: Dār al-Jayl, 1992.

Al-Asqalani, Ibn Hajar Ahmad bin Ali. Talkhị̦ al-Habir. Juz III. Madinah: t.p, 1964.

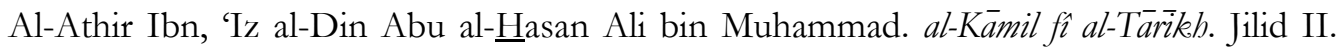
Beirut: Dār al-Ṣàdr, 1979.

Al-Athir Ibn, Majd al- Din Mubarak bin Muhammad. al-Nihāyah fi Garib al-Hadith wa alAthar. Juz I. Beirut: Dār al-Fikr, t.th.

Baidhawy, Zakiyuddin. Kredo Kebebasan Beragama. Jakarta: PSAP, 2006.

Al-Baihaqi, Ahmad bin Husain; Abu Bakar. Sunan al-Kubrā li al-Baihaqī. Juz VII-VIII. Diedit oleh Muștafá 'Abd Qādir al-'Ațā'. Makkah: Maktabah Dār al-Bāz, 1994.

Baqy, Muhammad Fuad Abd. al-Mu'jam al-Mufahras li Alfăzal-Qur'an al-Karim. Beirut: Dār al-Fikr, 1994.

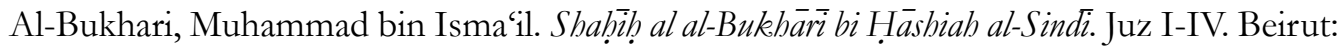
Dār al-Fikr; 1994.

Al-Darimi, Abu Muhammad 'Abdullah bin Bahram. Sunan al-Dārimiy. Juz II. Beirut: Dār alFikr, 2005.

Al-Dhahabi, Muhammad bin Ahmad. Siyar A'lam al-Nubala'. Juz V. cet IX. Diedit oleh Shu'ayib al-Arnawūt dan Muhammad Nu'aym al-'Arqusūsiy. Beirut: Mu'assasah alRisālah, , $1413 \mathrm{H}$. 
ljtihad, Jurnal Wacana Hukum Islam dan Kemanusiaan, Volume 14, No. 1, Juni 2014:21-39

Al-Dimashqi ‘Abd Hayyi bin Ahmad Ibn Imad. Shadharät al-Dhahab fī Akbbär Man Dhahab. Jilid I. Beirut: Dār al-Kutub al-'Ilmiyyah, 1998.

Al-Haithami, Ali bin Abu Bakar. Majma' al-Zawāìd wa Manba' al-Fawà'id. Juz VI. Beirut: Dār al-Kutub al-'Tlmiyyah, 1988.

Hanbal, Abu Abdillah Ahmad Ibn. al-Musnad Aḥmad bin Hanbal. Jilid I, III, IV-VI. Beirut: Dār al-Fikr, t.th.

Kasimin, Amran. Satu Analisa Mengenai Murtad. Kuala Lumpur: Pustaka Mizan, 1990.

Khadduri, Majid. War and Peace in the Law of Islam. Clark New Jersey: The Lawbook Exchange, LTD, 2006.

Little, David et. al. Human Rights and the Conflict of Cultures: Western and Islamic Perspectives. Alih bahasa Riyanto berjudul: Kajian Lintas Kultural Islam-Barat: Kebebasan Agama dan HakHak Asasi Manusia. Yogyakarta: Academia, 1997.

Al-Ma'afiri, ‘Abd Malik Ibn Hisyam. al-Sïrah al-Nabawriyyah. Juz IV. Cairo: Dār al-Ḥadìth, 2004.

Manzur, Muhammad bin Mukarram Ibn. Lisān al-Arab. Jilid I, XV, cet. I. Beirut: Dār Shādr, t.th.

Al-Maqdisi, Abdullah bin Ahmad Ibn Qudamah. al-Mugnì 'alā Mukbtasar al-Kharqīi. Juz IX. Beirut: Dār al-Fikr, 1405 H/1985.

Al-Naisaburi, Muhammad bin Abdullah al-Hakim. al-Mustadrak 'ala Ṣahịhain. Juz III. Diedit oleh Mustafa 'Abd Qadir al-'Ata'. Beirut: Dār al-Kutub al-'Ilmiyyah, 1990.

Al-Nasa'i, Abu 'Abd Rahman Ahmad bin Shu'ayib. Sunan al-Mujtabā al-Nasäiy. Jilid I, vol I. Jilid IV, vol VII-VIII. Diberi H̦äshizah oleh al-Sindi dan notasi oleh Shidqi Jamil al'Aț̣āar. Beirut: Dār al-Fikr, 1995.

Nasif, Hafniy dkk. Qawa'id al-Lugah al-Arabiyyah. Surabaya: al-Hikmah, t. th.

Al-Nawawi, Abu Zakariyya Yahya bin Sharaf al-Din. Shahịh Muslim bi Sharh al-Nawawi. Jilid VI, vol. XII. Beirut: Dār al-Fikr, 2000.

Qal'aji, Muhammad Rawwas dan Hamid Sadiq Qanibi. Mu'jam Luqah al-Fuqahä'. Cet. I. Beirut: Dār al-Nafāis, 1985.

Al-Qizwini, Abu Abdillah Muhammad bin Yazid. Sunan Ibn Mājah. Juz II. diedit oleh Shidqi Jamīi al- 'Aț̣ār. Beirut: Dār al-Fikr, 2004.

Al-Qushairi, Abu Husein Muslim bin Hajjaj al-Naisaburi. Shaḩịh Muslim. Jilid II. Beirut: Dār al-Fikr, 1993.

Sachedina, Abd Aziz. The Islamic Roots of Democratic Pluralism. New York: Oxford University Press, 2001.

Sa‘di, Abu Jayb. al-Qāmus al-Fiqh Lugatan wa Isțilăhan. Damaskus: Dār al-Fikr, 1998. 
Al-San'ani, 'Abd Razzaq bin Hammam. Musannaf 'Abd Razžàq. Juz X. Diedit oleh Habỉb alRaḥmān al-A'ẓamiy. Beirut: Maktabah al-Islāmi, $1403 \mathrm{H}$.

Sanu, Qutub Mustafa. Mu jam Muștalahạt Ușül al-Figh. Damaskus: Dār al-Fikr, 2000.

Syuhbah, Muhammad Abu. al-Hudūd fì al-Isläm wa Muqāranatuhä bi al-Qawānin al-Wasfiyyah. Cairo: Silsilah al-Buhūth al-Islāmiyyah, 1974.

Al-Sijistani, Sulaiman bin Ash'ath. Sunan Abì Dāud. Juz II, IV. Diedit oleh Shidqī Jamīl al'At\}t\}āar. Beirut: Dār al-Fikr, 2003.

Al-Tabarani, Abu Qasim Sulaiman bin Ahmad. Mu'jam al-Kabir. Juz XVII. Diedit oleh Hamdiy bin Abd Majid al-Salafiy. Mouṣol: Maktabah al-'Ulūm wa al-Hikam. 1983.

Al-Tabari, Muhammad bin Jarir. Tarikeh al-Ṭabar̄. Juz II. Beirut: Dār al-Kutub al-'Ilmiyyah, $1407 \mathrm{H}$.

Tim Penyusun. Ensiklopedi Hukum Islam. Jilid 3. Jakarta: PT Ichtiar Baru Van Hoeve, 1999.

Al-Turmudhi, Abu 'Isa Muhammad bin 'Isa bin Surah. Sunan al-Turmudhì. Juz I, III-IV. Diberi notasi oleh Shidqi Jamil al-'Attar. Beirut: Dar al-Fikr, 2003.

Zakariyya, Ahmad bin Faris bin. Mujam Maqāìis al-Lugah. Jilid I-VI. Beirut: Dār al-Jayl, 1991.

Al-Zuhri, Sa‘ad Ibn Abu Abdillah Muhammad al-Basri. Al-Ṭabaqāt al-Kubrā. Juz II-III. Beirut: Dār al-Shādr, t. th. 